\title{
Histology of the lacrimal gland in keratoconjunctivitis sicca
}

JOHN WILLIAMSON*, A. A. M. GIBSON**, T. WILSON†, J. V. FORRESTER*, K. WHALEY

From the *Eye Department, Southern General Hospital, The **Department of Pathology, Yorkhill $\overrightarrow{0}$ Hospital, The $\dagger$ Tennent Institute of Ophthalmology, University Department of Ophthalmology, $\vec{\omega}$ Western Infirmary, and The \$Centre for Rheumatic Diseases, University Department of Medicine, Royal Infirmary, Glasgow

The histology of Sjögren's syndrome, which is defined as keratoconjunctivitis sicca (KCS)윽 with xerostomia and rheumatoid arthritis, for the purpose of this communication, has been studied post mortem either in single cases or in series of not more than three patients $Z$

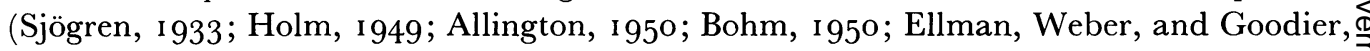
I95I ; Morgan and Raven, I952; Cardell and Gurling, I954; Szanto, Farkas, and Gyulai 코 I957; Funatsu and Eguchi, I957; Bucher and Reid, r959; Bain, I96o; Bloch, Buchanan, Wohl, and Bunim, ig65).

The lacrimal and salivary glands, and the mucous glands of the respiratory traథ; mouth, and upper oesophagus are typically involved. However, most of the observătions on lacrimal gland structure were recorded in severe cases of KCS and in patients who had died as a result of the severe complications of arthritis or another connective tissue disease. The primary purpose of this study was to investigate the histology of the lacrimal gland in patients currently suffering from KCS.

Patients with KCS and xerostomia, but no evidence of connective tissue disease, may be classified as suffering from the "sicca syndrome" (Bloch and others, i965). Lacrimalo gland tissue from such patients was studied to determine any features that may differen-ఫั tiate the "sicca syndrome" from Sjögren's syndrome.

Furthermore, reduced Schirmer II tear tests may be demonstrated in a number of rheumatoid arthritic patients who have no evidence of punctate or filamentary keratitis. $\dot{\varnothing}$ For study purposes, these patients may be regarded as cases of "possible" Sjögren's syndrome. Lacrimal gland biopsies were obtained from a sample of patients with "possible"은 Sjögren's syndronie in an attempt to elucidate the validity of this classification.

According to Manschot ( I 96I), systemic corticosteroids or adrenocorticotrophic hormone therapy may be effective in controlling acute exacerbations of Sjögren's syndrome and,,$-\infty$ therefore, may be expected to modify the histological appearances of the lacrimal gland. N Thus particular note was taken of any history of systemic steroid therapy.

\section{Materials and methods}

PATIENTS STUDIED

Biopsies of the lacrimal gland were obtained from 29 female patients (eighteen Sjögren's syndrome, $\frac{\mathrm{O}}{\mathrm{T}}$ five sicca syndrome, and six "possible" Sjögren's syndrome). In addition, the lacrimal glands of 
ten age-matched patients, who had died from a variety of medical disorders not known to be related to rheumatoid arthritis or connective tissue disease and who had no history of ocular disease, were examined post mortem (Table I).

Table I Ages of patients and controls and histology of lacrimal gland

\begin{tabular}{|c|c|c|c|c|c|c|c|}
\hline \multirow{2}{*}{ Clinical diagnosis } & \multirow{2}{*}{ Number of patients } & \multicolumn{2}{|c|}{$\operatorname{Age}(y r s)$} & \multicolumn{4}{|c|}{ Histology (Stage) } \\
\hline & & Mean & Range & $O$ & $I$ & $I I$ & III \\
\hline Sjögren's syndrome* & 18 & $6 r \cdot 4$ & $5^{2-80}$ & I & - & 9 & 8 \\
\hline Sicca syndrome $\dagger^{* *}$ & 5 & $6 \mathrm{r} \cdot \mathrm{O}$ & $55^{-81}$ & - & 2 & 2 & I \\
\hline Possible Sjögren's syndrome & 6 & $6 o \cdot 2$ & $55-75$ & 6 & - & - & - \\
\hline Controls & ro & $64 \cdot 0$ & $3^{2-76}$ & Io & - & - & - \\
\hline \multicolumn{8}{|l|}{ Breast cancer (2) } \\
\hline \multicolumn{8}{|l|}{ Coronary thrombosis $(3)$} \\
\hline Cerebrovascular disease (5) & & & & & & & \\
\hline
\end{tabular}

* Two also had systemic lupus erythematosus

$\dagger$ One had biliary cirrhosis

** Three also had osteoarthritis

The diagnosis of rheumatoid arthritis was based on the criteria of the American Rheumatism Association (Ropes, Bennett, Cobb, Jacox, and Jessar, 1959).

\section{LAGRIMAL GLAND BIOPSY TECHNIQUE}

Since removal of part of the palpebral portion of the lacrimal gland entails destruction of the excretory ducts, the orbital section was chosen for biopsy. Each patient understood the reason for the operation and that it was carried out on a voluntary basis. After infiltration with local anaesthesia, 2 per cent. lignocaine without adrenaline, the skin was incised for a distance of $1.5 \mathrm{~cm}$. from the lateral orbital tubercle towards the medical canthus, $0.5 \mathrm{~cm}$. below and parallel to the superior orbital margin. Underlying fascia and muscle were separated by blunt dissection until the smoky-blue periorbital membrane was identified where it is closely attached to the rim of the orbit. Incision of the periorbital membrane resulted in protrusion of periorbital fat which was easily replaced with a probe. Toothed forceps were inserted into the superior lateral angle of the orbital roof and a piece of lacrimal gland tissue, no greater than I cu. mm., was abscised. The specimen was transported in formal saline. The skin wound was closed with three interrupted black silk sutures, no haemostatic or subcuticular stitches being necessary. Eyelid appearances returned to normal within 14 days and no complications were encountered. Histology was studied on paraffin sections $6 \mu$ thick stained by haematoxylin and eosin. Considerable care was taken to give the pathologist no information regarding the source of the lacrimal tissue.

\section{Results}

Table I shows the range of disorders from which the patients were suffering. Two of the 24 rheumatoid arthritic patients also had systemic lupus erythematosus and three of the five "sicca syndrome" group also had osteoarthritis. There was no significant difference in the mean age and age range of the groups studied.

Four distinct histological stages were recognized in this study (Table I): 
Stage o Normal lacrimal gland

The lacrimal gland consists of tubulo-racemose tissue with short branched tubules and masses of lobules interspersed with fat (Fig. I). Plasma cells are a normal feature of the interacinous and interlobular connective tissue; lymphocytes are less frequently detected.

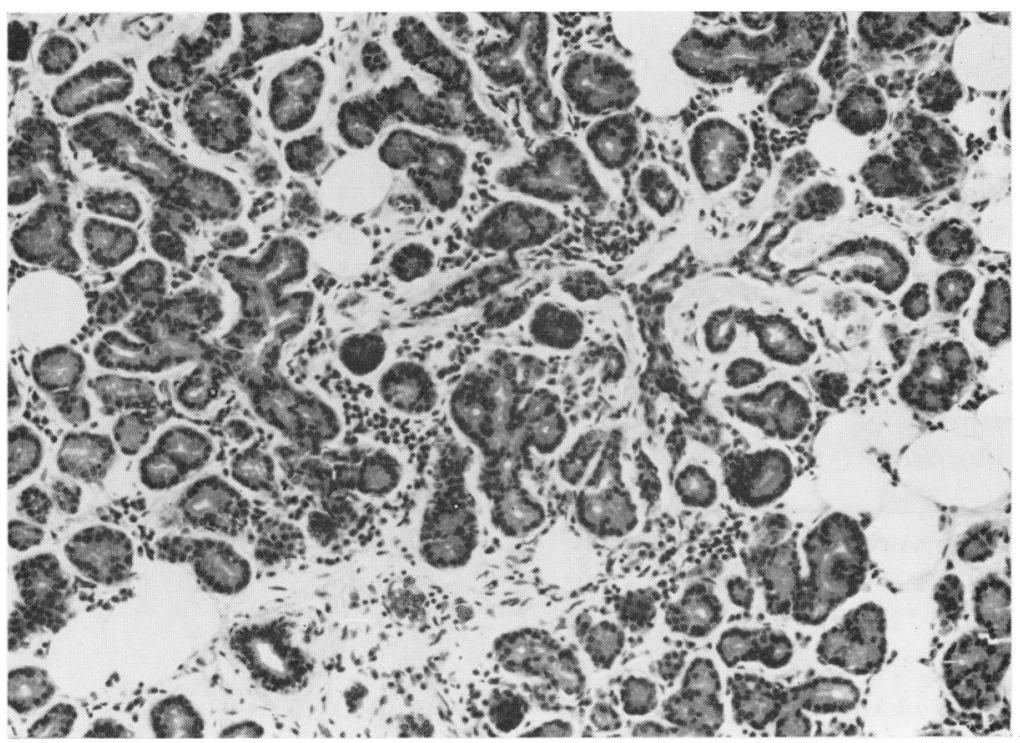

FI G. I Stage $O$.

Normal tissue. $\times 5$

\section{Stage I Mild chronic inflammation}

The salient features in these cases are abnormal arrangement of the ducts, mild lymphocytic infiltration, and slight intralobular fibrosis (Fig. 2).

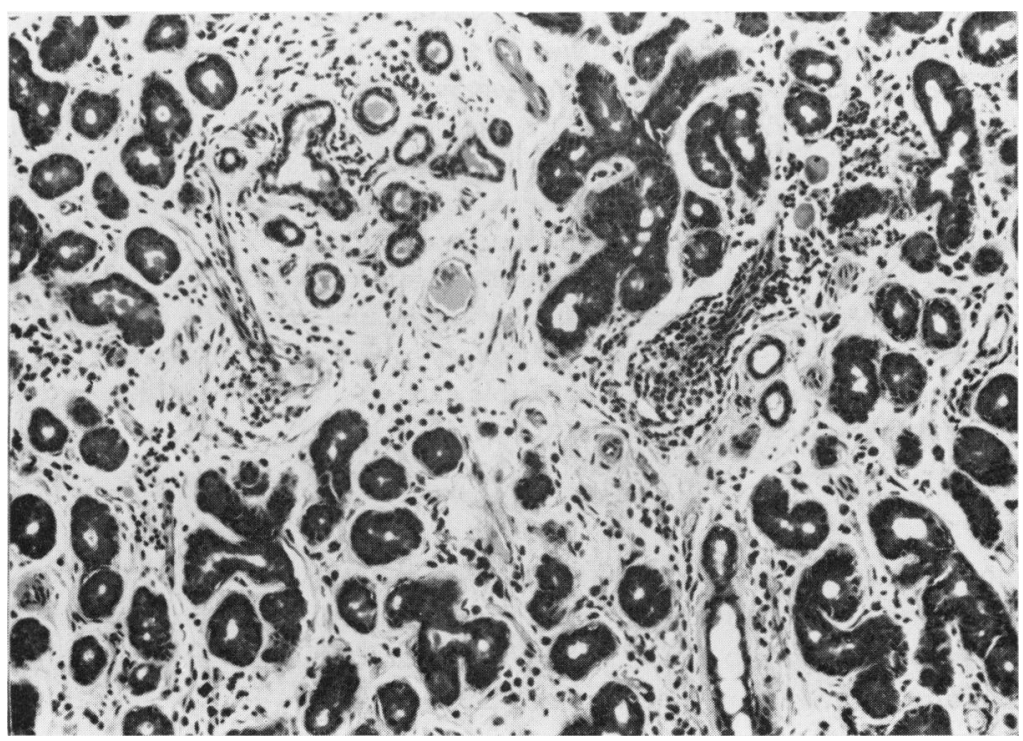

FIG. 2 Stage $I$.

Mild chronic in-

flammation, showing

abnormal duct

arrangement. $\times 5$ 
Stage II Severe chronic inflammation

Total destruction of the normal lobular pattern, dense infiltration with lymphocytes, aggregating into lymph follicles and progressive acinar atrophy (Fig. 3) are the features of this grade.

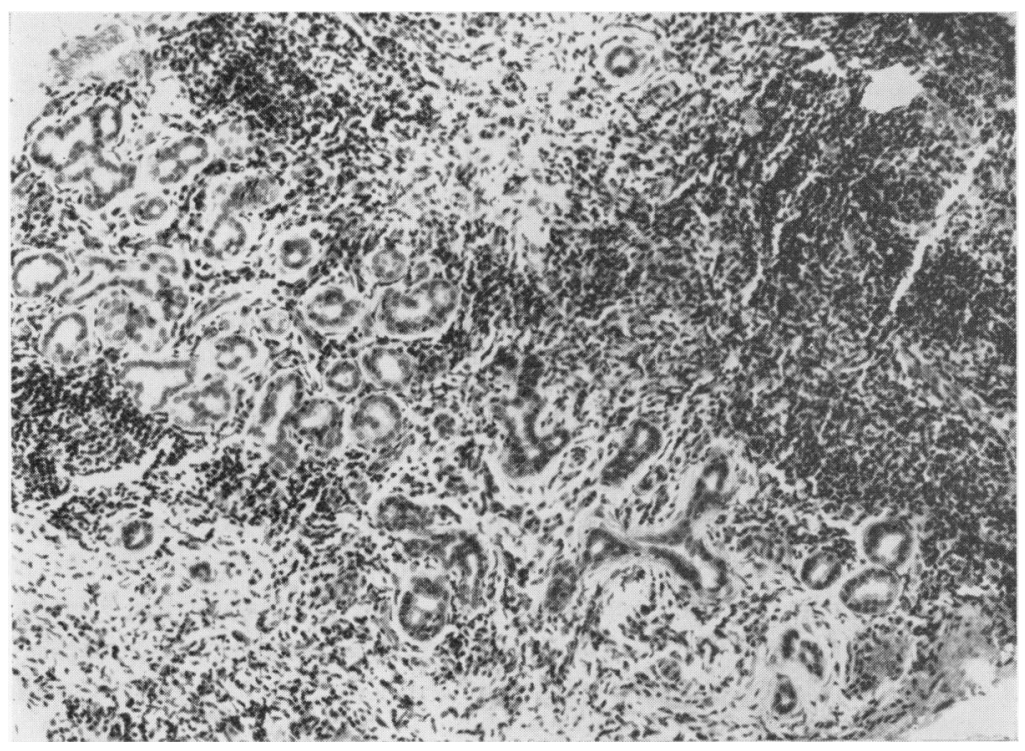

FIG. 3 Stage II. Severe chronic inflammation. $\times 5$

\section{Stage $11 I$ Late fibrosis}

Fibrous tissue is increased. Few acinar cells remain (Fig. 4).

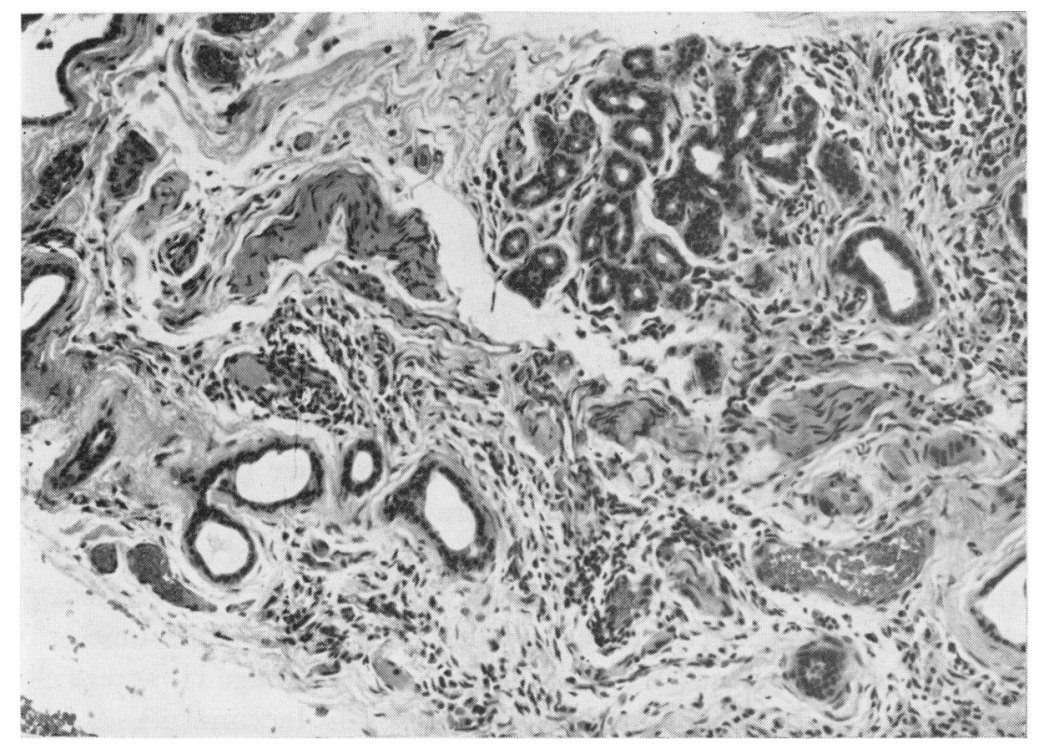

FIG. 4 Stage 111.

Late fibrosis. $\times 5$

All of the ten post mortem control specimens and the six biopsies from patients suffering from "possible" Sjögren's syndrome showed normal lacrimal glands. Only one patient suffering from definite KCS had a normal tissue biopsy. 
This patient was a 50-year-old woman with a 2-year history of seropositive rheumatoid arthritis? xerostomia, and dry eyes. Her white blood count, serum globulin, and liver function tests were normal, the erythrocyte sedimentation rate being slightly raised to $25 \mathrm{~mm}$. in the first hour. Tests for antinuclear factor and salivary duct antibody were negative and $x$-ray and functional grades weres zero. All the evidence therefore indicated that the patient had mild chronic rheumatoid arthritiso and KCS when the biopsy was taken.

The remaining seventeen Sjögren's syndrome and five sicca syndrome patients all showed abnormal lacrimal gland tissue (Table I).

Mild chronic inflammation (Stage I) was detected in one of the sicca syndrome patients who was also suffering from primary biliary cirrhosis.

This was a 67-year-old woman with a 6-year history of liver disease without arthropathy and aू 6 months' history of dry eyes. Salivary duct autoantibodies were present but there was no clinicalo. serological, or $x$-ray evidence of rheumatoid arthritis.

The only other patient with mild chronic inflammation (Stage I) was a 75-year-old woman with a 6-year history of dry eyes and a dry mouth (sicca syndrome).

Eleven patients, nine with Sjögren's syndrome and two with the sicca syndrome, had? severe chronic inflammatory changes (Stage II) and the late results of inflammation $\bar{z}$ (Stage III) were recorded in the remaining nine patients, eight with Sjögren's syndrome and one with sicca syndrome (Table II). No histological features distinguished the lacri-ב mal glands of patients with Sjögren's syndrome from those with the sicca syndrome.

Table II Severity of lacrimal gland destruction related to duration of keratoconjunctivitis sicca

\begin{tabular}{|c|c|c|c|c|c|}
\hline \multirow{2}{*}{ No. of patients } & \multirow{2}{*}{$\begin{array}{l}\text { Duration of } K C S S \\
(y r s)\end{array}$} & \multicolumn{4}{|c|}{ Histology (Stages) } \\
\hline & & $O$ & $I$ & $I I$ & $I I I$ \\
\hline 4 & $0-I$ & - & I & 3 & - \\
\hline 4 & $\mathbf{I}-3$ & I & - & 3 & - \\
\hline 3 & $3-5$ & - & - & 一 & 3 \\
\hline 4 & $5-7$ & - & I & 3 & 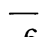 \\
\hline & $7+$ & 二 & - & 2 & 6 \\
\hline Total 23 & & I & 2 & I I & 9 \\
\hline
\end{tabular}

Severity of lacrimal gland destruction tended to be greater with increased duration of ocular disease (Table II). Thus none of the eight patients who had suffered from KCS for less than 3 years had Stage III changes. On the other hand, three patients with ao 3- to 5-year history showed only mild or severe chronic infiltration (Stages I and II). N The groups are too small to compare with respect to severity of arthritis.

Five of the patients with Sjögren's syndrome had received steroid therapy for periods varying from 2 to ro years in an average daily dose of $5 \mathrm{mg}$. prednisolone or its equivalent per day. Stage III (late) changes were described in four and Stage II (severe chronic) in on case. Steroid therapy had not prevented involvement of the lacrimal glands in these patients. All five patients had suffered from Sjögren's syndrome for more than 5 years and had ${ }^{\text {? }}$ received systemic steroids during that time. Nevertheless, no difference in histology could be determined between these patients and the remaining group who had never品 received systemic steroids and who had also suffered from KGS for more than 5 years. 


\section{Discussion}

Biopsy of the orbital portion of the lacrimal gland in patients suffering from KCS has not previously been recorded in a large series of patients. From our perusal of the literature, it appears that the lacrimal glands of no more than three patients have been examined post mortem in any one group, and in most instances only a single case has been reported. For these reasons, a series of 29 female patients depicting a range of involvement with KCS was selected for lacrimal gland biopsy. The specimens were classified into four stages: normal, mild chronic inflammation, severe chronic inflammation, and a late fibrotic phase. In general, the severity of destruction parallelled the duration of the ocular disease.

Sjögren (1933), in discussing a patient who had suffered from KCS for 2 years, described chronic round cell infiltration around the excretory ducts and to a lesser extent in the interlobular and interacinous connective tissue. Secondary changes consisted of sclerosed connective tissue and degeneration in the epithelial cells near the infiltrated areas. Holm (1949), Ellman and others (I95I), and Haas (I95I) reported their findings in patients who had suffered from Sjögren's syndrome for 6,5 , and 4 years respectively. Their descriptions include destruction of the normal lobular pattern, infiltration with lymphocytes, and increase in fibrous tissue. Without examination of the sections, it is difficult to apply our classification to those specimens. However, the severity of lacrimal gland involvement in relation to the duration of the disease suggests that their findings are compatible with our Stages II and III.

Furthermore, the investigation of two groups of three pateints was reported by Cardell and Gurling (1954) and Bloch and others (1965).

The first authors described two female patients who had suffered from Sjögren's syndrome for 4 and 5 years respectively. Both had severe filamentary KCS and one also had polyarteritis nodosa. Both of those patients are relevant to this report in that they had been treated with ACTH and/or cortisone preparations. Nevertheless, the lacrimal glands contained areas densely infiltrated with chronic round cells, with some lymph follicle formation. Severe degeneration and atrophy of the parenchyma were widespread, as was replacement with fibro-adipose tissue. The specimens from these two patients could be classified as Stages II and III and, as in our series, the severity of the pathological changes seemed to have been unaffected by steroid therapy. Their third case was a man aged 73 years who had had KCS for 4 years without evidence of rheumatoid arthritis (sicca syndrome). Nevertheless, he had severe lacrimal gland destruction, obliterative endarteritis, and replacement of the normal glandular structure with fibro-adipose tissue. These findings substantiate our view that lacrimal gland changes are probably identical in both Sjögren's syndrome and KCS without evidence of connective tissue diseases.

In our series the lacrimal glands of four patients with sicca syndrome were examined and no features were found to differentiate them from patients with Sjögren's syndrome.

In the second group of three patients, Bloch and others (1965) described the pathology in the parotid gland of a 66-year-old woman who had suffered from Sjögren's syndrome for i I years, and stated that the lacrimal gland changes were similar.

They identified infiltration with small mononuclear cells and lymphocytes and noted that remnants of acinar components were sparse, located at the periphery of the lobules. Some of the ducts were distended with secretion, but the normal architecture of the lobules was preserved. It is interesting that they, like Cardell and Gurling, were able to identify occasional plasma cells.

In our series plasma cells were not identified once lymphocytic infiltration had begun. The second case of Block and others (1965), a 49-year-old woman with progressive systemic sclerosis, had suffered from Sjögren's syndrome for I 4 years. The acinar atrophy was marked, and 
there was only slight lymphocytic infiltration. Replacement with fibro-adipose tissue was extensive. This description clearly falls into Stage III of the present series. Their third case was that of a 68 -year-old woman who had suffered from Sjögren's syndrome for I year. The gland examined showed atrophy of acinar tissue and chronic inflammatory cell infiltration. Without more details, it is difficult to identify the stage of involvement in this particular case.

In our series, neither the ten age-matched patients examined post mortem, nor the six

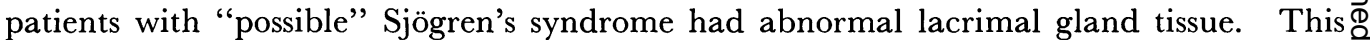
would suggest that the definition of Sjögren's syndrome as a chronic inflammatory disease is valid, and it would appear from our biopsy findings that KCS without evidence of $\overrightarrow{0}$ connective tissue disease is also a chronic inflammatory disorder. However, Radnót $\overrightarrow{-}$ (1939) recorded over 30 years ago that patients over the age of 50 years undergo pro- $\omega$ gressive atrophy of the lacrimal glands and that infiltration with lymphocytes is a normal응. occurrence in this and older age groups. The mean age of the control group in this series or was 64 years, yet no abnormalities of the lacrimal glands were detected. It would appear reasonable to suggest that more extensive examinations of "normal" lacrimal gland tissue, $\infty$ especially in older age groups, should be undertaken.

\section{Summary}

Histology of the lacrimal gland was studied in a series of 29 female patients, eighteen of whom had Sjögren's syndrome, five the sicca syndrome, and six "possible" Sjögren's 큼 syndrome. Furthermore, the lacrimal glands of ten patients with no history of ocular or $\stackrel{\Phi}{-}$ connective tissue disease were examined post mortem.

The appearances were classified into normal, mild chronic inflammation, severe chron inflammation, and late fibrosis (Stages O, I, II, and III). Both the controls and th "possible" cases of Sjögren's syndrome had normal lacrimal glands. Those with Sjögren's syndrome and the "sicca syndrome" showed abnormal lacrimal gland histology, the extent of which was related to the duration of the keratoconjunctivitis sicca. No specific features distinguished the lacrimal glands of Sjögren's syndrome from those of the sicca syndrome. In addition, long-term systemic steroid therapy did not seem to have reduced $\rightrightarrows$ the extent of lacrimal gland pathology in the series examined.

\section{References}

Allington, H. v. (1950) Arch. Derm. Syph., 62, 829

bain, G. o. (1960) Canad. med. Ass. J., 82, 143

Bloch, к. J., Buchanan, w. w., wohl, м. J., and bunim, J. J. (1965) Medicine (Baltimore), 44, I87

вонм, А. (1950) Münch. med. Wschr., 92, 955

Bucher, U. G., and ReID, L. (1959) Brit. F. Dis. Chest, 53, 237

Cardell, B. s., and GURling, K. J. (1954) F. Path. Bact., 68, 137

ellman, P., Weber, F. P., and Goodier, T. E. W. (195I) Quart. F. Med., 20, 33

funAtsu, H., and EgUchi, F. J. (1957) f. clin. Ophthal., II (English Summary), I 33

HAAS, E. (1951) Virchows Arch. path. Anat., 320, 264

HOLm, s. (1949) Acta ophthal. (Kbh.), Suppl. 33, p. I

manschot, w. A. (196I) Adv. Ophthal., I1, I [Bibliotheca ophthalmologica Fasc. 58]

MORGAN, A. D., and RAVEN, R. W. (1952) Brit. F. Surg., 40, I 54

RADNót, м. (1939) "Die pathologische Histologie der Tränerdrüse”, p. 64. Karger, Basel.

Quoted by Holm (1949)

ropes, M. W., BenNett, G. A., совв, s., JAGox, R., and Jessar, R. A. (1959) Ann. rheum. Dis., r8, 49 sJögren, H. (1933) Acta ophthal. (Kbh.), Suppl. 2. (Trans. J. B. Hamilton, 1943)

szanto, L., FARKAS, K., and GyUlaI, E. (1957) Rheumatism, r3, 6o 